Pfeiffer HH, Ghosh S, Thiele EA. Safety and tolerability of the ketogenic diet in pediatric epilepsy: Effects of valproate combination therapy. Epilepsia September 2005;46:15331538). (Reprints: Dr EA Thiele, Pediatric Epilepsy Program, Massachusetts General Hospital, 175 Cambridge St, Suite 340, Boston, MA 02114).

COMMENT. The authors' experience shows that concerns regarding possible adverse effects of cotherapy with the KGD and VPA in refractory epilepsy should not exclude a trial of the simultaneous use of these agents, with careful monitoring. Since seizure control was apparently not related to degree of ketosis in the above study, the introduction of the diet using the original Mayo Clinic regimen (with lower fat:carbohydrate ratios) rather than the Hopkins method of initiation (with a 4:1 ratio) should lower the incidence of adverse events and heighten the tolerability. (Millichap JG et al. Epilepsia 1964;5:239-255; Am J Dis Child 1964;107:593-604; Ped Neur Briefs Feb 2005;19:12-13).

In a trial of the KGD in 20 patients with Dravet syndrome (severe myoclonic epilepsy in infants), $10(77 \%)$ of the 13 children who remained on the diet at 1 year had achieved a $>75 \%$ reduction in seizures, and quality of life was improved. (Caraballo $\mathrm{RH}$ et al. Epilepsia Sept 2005;46:1539-1544).

\title{
OMEGA-3 FATTY ACID SUPPLEMENTS FOR CHRONIC EPILEPSY
}

Omega-3 fatty acid (FA) supplements (1g EPA and $0.7 \mathrm{~g}$ DHA daily) were used in the treatment of 58 patients with refractory epilepsy, in a 12-week double-blind, placebocontrolled trial conducted by researchers at the UCL Institute of Neurology, London, UK. In the first 6 weeks of treatment, a $50 \%$ reduction in seizures was obtained in 5 of 29 supplemented patients whereas none $(0 / 27)$ showed benefit with placebo $(\mathrm{P}=0.087)$. In the second 6 weeks, this apparent initial trend toward significant difference in seizure control was not sustained: $4 / 30$ in the supplemented group and 5/27 in placebo group showed reduction in seizure frequency. The need for intermittent therapy with diazepam did not differ between the two groups. Status epilepticus occurred in one patient in each group. FA supplements produced an expected increase in plasma EPA and DHA concentrations and a reciprocal fall in omega-6 arachidonic and linoleic acid concentrations. Antiepileptic drug levels were unaffected. (Yuen AWC, Sander JW, Fluegel D et al. Omega-3 fatty acid supplementation in patients with chronic epilepsy: a randomized trial. Epilepsy Behav September 2005;7:253-258). (Respond: Ley Sander. Fax: +44 1494 872699).

COMMENT. Experimental studies in animals have shown that EPA and DHA as well as omega-6 FA will raise seizure thresholds, and omega-3 FA will lower plasma inflammatory mediators, which may lead to reduction in seizure susceptibility (Bailey EE et al. Epilepsy Behav 2005;6:4-8). In a recent report of the benefits of fatty acid supplements in children with reading disabilities and ADHD, a combination of omega- 3 and - 6 FA was recommended (Richardson AJ et al. Pediatrics 2005;115:1360-1366; Ped Neur Briefs May $2005 ; 19: 33-34)$. Future trials of FA supplements in patients with refractory epilepsy should perhaps include both omega-3 and $-6 \mathrm{FA}$. 